\title{
The Implications of Maternal Overweight and Obesity on the Course of Pregnancy and Birth Outcomes
}

\author{
Anna-Maria Siega-Riz • Anna-Maria Siega-Riz • \\ Barbara Laraia
}

Published online: 23 August 2006

(C) Springer Science+Business Media, Inc. 2006

\begin{abstract}
The increasing prevalence of overweight and obesity among women of childbearing age is a growing public health concern in the United States. The average body mass index (BMI) is increasing among all age categories and women enter pregnancy at higher weights. Women are also more likely to retain gestational weight with each pregnancy. Women who are overweight (BMI 25-30) and obese $(\mathrm{BMI} \geq 30)$ are at greater risk of adverse reproductive health outcomes compared to women of normal weight status (BMI 19.8-25). This article provides an overview of the complications associated with maternal overweight and obesity including diabetes, pre-eclampsia, c-sections, and birth defects. We present updated information on the weight trends among women. Finally, we present an overview of the prevention studies aimed at adolescents and women prior to pregnancy.
\end{abstract}

Keywords Obesity · Nutrition · Women · Pregnancy · Postpartum

A.-M. Siega-Riz · B. Laraia

Department of Nutrition, School of Public Health, University of North Carolina,

Chapel Hill, NC

A.-M. Siega-Riz

Department of Nutrition and Epidemiology, School of Public Health, University of North Carolina,

Chapel Hill, NC

A.-M. Siega-Riz $(\square)$

Carolina Population Center, University of North Carolina at Chapel Hill,

CB \# 8120 University Square, Chapel Hill, NC, 27516-3997

e-mail: am_siegariz@unc.edu

\section{Introduction}

The effect of maternal nutritional status prior to pregnancy on birth outcomes is of great public health importance. Epidemiological studies have shown a clear association between maternal pregravid weight and birth outcomes. As a marker of nutritional status, a woman's pregravid body mass index $\left(\mathrm{BMI}=\mathrm{kg} / \mathrm{m}^{2}\right)$, if low $(<19.8 \mathrm{BMI})$, may reflect chronic nutritional deficiency whereas a high BMI ( $>26.1 \mathrm{BMI})$ reflects an imbalance between energy intake and expenditure, and thus varying degrees of adiposity [1]. The effects of each on birth outcomes differ, with low BMI being associated with intrauterine growth retardation (IUGR), preterm birth, and iron deficiency anemia [2-5]. Whereas, BMI above the normal range of 19.8 to 26.1 (IOM 1990) is associated with a number of adverse reproductive health outcomes. For example, infertility [6] gestational diabetes [7], pregnancy induced hypertension and pre-eclampsia [8], birth defects [9], large for gestational age (LGA) or macrosomia (>4500 g) [10], cesarean sections [11-13], prolonged labor [14], and recently postpartum anemia [15-17] have all been associated with maternal overweight yet the exact mechanisms have not been identified. The purpose of this paper is to describe an overview of the complications associated with maternal overweight and obesity; present updated information on the weight trends among women; and review prevention studies aimed at adolescents and women prior to pregnancy.

\section{Prevalence of overweight and obesity among women of childbearing age}

Until recently, most studies on the topic of maternal pregravid weight focused on the lower end of the weight spectrum; however, with the shift in body weight that has occurred 
globally, more recent research has examined the effect of overweight and obesity on birth outcomes. Obesity world wide (>30 BMI) now exists at a prevalence of $15-20 \%$ and accounts for $2-7 \%$ of the total health care costs [18]. In the US, the latest NHANES survey (1999-2002) indicate that $26 \%$ of non-pregnant women $20-39$ years of age are overweight (25-29.9 BMI), and $29 \%$ are obese ( $>29.9 \mathrm{BMI}$ ) [19]. On average, obesity among all women appears to have peaked at 33\% with no appreciable increase between 19992000 and 2003-2004 [20].

\section{Determinants of overweight among women}

A higher proportion of women of child bearing age are overweight or obese compared to men, and women of younger or older ages. In addition, upwards of $80 \%$ of African American women are either overweight or obese [19]. Using 20032004 data from NHANES, non-Hispanic black women are twice as likely to be obese than their non-Hispanic white counterparts (OR 2.01, 95\% CI, 1.76, 2.29) [20]. Among individuals with less than a high school education, the prevalence of obesity was roughly twice that of college graduates [21]. Paradoxically, low-income households appear to have a higher risk of obesity [22], although, at the same time they are more likely to be at risk of food insecurity. Household food insecurity has been associated with increased BMI [23] and an increased risk of overweight [24] in women, but not among men or children [25-27].

\section{Influences of adolescent overweight on reproductive health}

Moreover, thirty percent of non-pregnant adolescent girls 12-19 years of age are considered overweight or at risk, based on a BMI for age at the 85th percentile or higher [19]. Excessive weight gain at younger ages is associated with earlier menarche, especially among black and Hispanic girls. Younger and more severely obese girls reaching reproductive capacity perpetuate obesity if left untreated, directly through the influence of maternal weight on fetal origins and indirectly through maternal to child social and developmental interactions [28].

\section{Pregravid BMI is a predictor of gestational weight gain}

Among women who become pregnant, the shift towards higher pregravid weight also appears evident [29]. One study using a perinatal data base to ascertain weight before pregnancy for a 19 year period showed that the mean maternal weight of women at their first prenatal visit increased by $20 \%$ between 1980 and 1999, and the percentage of women weighing $>200 \mathrm{lbs}$ at that visit increased from 7.3 to $24 \%$ and for those weighing $>300 \mathrm{lbs}$ the percentage increased from 2 to $11 \%$ [30]. Another study using a perinatal data system of all live births from 8 contiguous counties in New York, an $11 \%$ increase in pregravid overweight and an $8 \%$ increase in pregravid obesity between 1999 and 2003 [29]. Not only are more women beginning pregnancy at a higher BMI, but women are also gaining in excess of the 1990 Institute of Medicine recommendation for gestational weight gain [1]. Specifically, and overweight and obese women are more likely to gain excessive gestational weight and keep it on after delivery [31-33]. In affluent countries, women retain some weight with each successive pregnancy, gaining more weight than their non-pregnant counterparts [34, 35]. These observations beg the far larger and more important question of how and when to intervene in order to optimize reproductive and individual health?

\section{Weight intervention studies}

Many research studies of dietary, physical activity and weight interventions focus on individuals who are already obese or experiencing co-morbidities such as heart disease, diabetes or cancer. In contrast, only a limited number of interventions have focused on weight loss and/or maintenance of optimal weight in the context of reproductive health. On one end of the spectrum, surgical interventions such as gastric bypass and lap-band surgeries have been successful among obese women of child-bearing age with a decrease of reported rates of gestational diabetes, macrosomia, cesarean section while achieving adequate weight gain $[36,37]$. Some interventions have been targeted to address obesity during adolescents, pregnancy, and the postpartum or inter-conceptional periods. These commonly have been school- or clinic-based in nature. School-based randomized intervention trails such as the Trial of Activity in Adolescent Girls (TAAG) are presently underway to determine if increased opportunities for moderate and vigorous activity may decelerate the age related decline in physical activity [38].

\section{Clinic-based interventions}

Clinic-based intervention usually begin with obesity management training for physicians because of the existence of a combination of a paucity of nutrition, physical and weight educational materials, lack of knowledge of how to counsel women, and lack of resources and personnel to assist with obesity management. For example, results from a survey of pediatricians found that only $12 \%$ of pediatricians reported 
high self-efficacy in obesity management, although $39 \%$ stated that physicians were important health care providers that could be effective with obesity management. Lack of non-MD staff reimbursement, of an on-site dietitian, and of patient educational materials were each highly associated with low self-efficacy in obesity management [39].

\section{Weight loss interventions}

Tsai and Wadden [40] conducted a systematic review of major commercial weight loss programs undertaken to provide physicians with information on components, cost, and efficacy of these programs. eDiets.com, Health Management Resources, Take off Pounds Sensibly, OPTIFAST, and Weight Watchers were represented in the academic literature. The review identified Weight Watchers as the least costly with maintenance of $3.2 \%$ loss of initial weight at two years. Medically supervised very-low-calorie diet programs had the greatest weight loss (approximately 15 to $25 \%$ of initial weight), but were associated with high costs and high attrition rates. Finally, Internet (i.e., eDiets.com) and organized self-help programs (i.e., Overeaters Anonymous) produced minimal weight loss. In a clinical intervention conducted among pregnant women, physicians were trained to chart and monitor gestational weight gain adequacy based on the Institute of Medicine weight gain recommendations. Women received five patient education newsletters by-mail with actionoriented messages of how to gain adequate weight in pregnancy. Findings indicated that low-income women who received the intervention were less likely to gain excessive gestational weight. Overweight low-income women were at a reduced risk to retain more than $2.7 \mathrm{~kg}$ of weight at one year [41]. A hospital based randomized control trail with an intensive stepped-care, behavioral intervention found that the intervention significantly decreased the percentage of normal weight women gaining in excess of the IOM recommendations [42].

\section{Significance of weight status during postpartum period}

The postpartum period is hypothesized to significantly contribute to overweight and obesity through pregnancy weight retention. Olson et al. [31] found that over $25 \%$ of women participating in a cohort study experienced major weight gain, defined as $4.55 \mathrm{~kg}$ or more, at one year postpartum. Gestational weight gain, postpartum exercise frequency, and food intake were all significantly associated with weight change from early pregnancy to one year postpartum. Lower income women who gained more than the IOM recommendation were at increased risk for major weight gain at one year postpartum. In a randomized trial of 40 overweight postpartum women receiving either a 12 week structured or self-directed diet and physical activity intervention, the structured intervention group had significant weight loss $(7.3 \mathrm{~kg})$, decrease in percent body fat $(6 \%)$ and no change in fatfree mass, whereas the self-directed group had no significant change at one year postpartum [43]. Randomized control trials are currently underway in low-income WIC populations receiving usual care or a multi-component intervention including home visits, group classes and monthly telephone counseling [44].

\section{Conclusion}

Given that the costs associated with treating obesity are so high and their limited success rates, the best strategy is to prevent obesity from occurring in the first place. However, prevention first requires a clear understanding of its etiology. Obesity is a chronic disease thought to develop from a complex interaction of genotype and environmental factors [45]. Our knowledge of how and why this disease develops is far from complete, but currently funded research projects are targeting the integration of social, behavioral, cultural, and biological factors. In addition, best practices at obesity prevention, treatment and optimal weight maintenance must be identified to provide practitioners with an array of strategies to help curb the ensuing epidemic.

\section{References}

1. Institute of Medicine. Nutrition during Pregnancy. Part I, Weight Gain. Washington, DC: National Academy Press; 1990.

2. Kramer M, Seguin L, Lydon J, Goulet L. Socio-economic disparities in pregnancy outcome: Why do the poor fare so poorly? Paediatric and Perin Epi 2000;14:194-210.

3. Kramer MS, Platt R, Yang H, McNamara H, Usher RH. Are all growth-restricted newborns created equal(ly)? Pediatrics. 1999;103:599-602.

4. Abrams B, Newman V. Small-for gestation-age birth: Maternal predictors and comparison with risk factors of spontaneous preterm birth in the same cohort. Am J Obstet Gynecol 1991;164: 785-90.

5. Siega-Riz AM, Adair LS, Hobel CJ. Maternal underweight status and inadequate rate of weight gain in the third trimester of pregnancy increases the risk of preterm delivery. J Nutr 1996;126:14653.

6. Zaadstra BM, Seidell JC, Van Noord PA, te Velde ER, Habbema JD, Vrieswijk B, Karbaat J. Fat and female fecundity: prospective study of effect of body fat distribution on conception rates. BMJ 1993;306:484-7.

7. Solomon CG, Willett WC, Carey VJ, Rich-Edwards J, Hunter DJ, Colditz GA, Stampfer MJ, Speizer FE, Spiegelman D, Manson JE. A prospective study of pregravid determinants of gestational diabetes mellitus. JAMA 1997;278:1078-83.

8. Thadhani R, Stampfer MJ, Hunter DJ, Manson JE, Solomon CG, Curhan GC. High body mass index and hypercholesterolemia: 
risk of hypertensive disorders of pregnancy. Obstet Gynecol 1999;94:543-50.

9. Anderson JL, Waller DK, Canfield MA, Shaw GM, Watkins ML, Werler MM. Maternal obesity, gestational diabetes, and central nervous system birth defects. Epidemiology 2005;16:87-92.

10. Larsen CE, Serdula MK, Sullivan KM. Macrosomia: influence of maternal overweight among a low-income population. Am J Obstet Gynecol 1990;162:490-94.

11. Cnattingius S, Bergstrom R, Lipworth L, Kramer MS. Prepregnancy weight and the risk of adverse pregnancy outcomes. N Engl J Med 1998;338:147-52.

12. Rosenberg TJ, Garbers S, Chavkin W, Chiasson MA. Prepregnancy weight and adverse perinatal outcomes in an ethnically diverse population. Obstet Gynecol 2003;102:1022-7.

13. Vahratian A, Siega-Riz AM, Zhang J, Troendle J, Savitz D. Maternal pre-pregnancy overweight and obesity and the risk of primary cesarean delivery in nulliparous women. Ann Epidemiol 2005;15:467-74.

14. Vahratian A, Zhang J, Troendle J, Savitz D, Siega-Riz AM. Maternal pre-pregnancy overweight and obesity and the pattern of labor progression in term nulliparous women. Obstet Gynecol 2004;104:943-51.

15. Bodnar LM, Siega-Riz AM, Cogswell M. High pregnancy body mass index increases the risk of postpartum anemia. Obes Res 2004; 12:941-8.

16. Bodnar LM, Siega-Riz AM, Miller WC, Cogswell ME, McDonald T. Who should be screened for postpartum anemia? An evaluation of current recommendations. Am J Epidemiol 2002;156:903-12.

17. Bodnar LM, Scanlon KS, Freedman DS, Siega-Riz AM, Cogswell ME. High prevalence of postpartum anemia among low-income women in the United States. Am J Obstet Gynecol 2001;185:43843.

18. WHO Global Strategy on Diet, Physical Activity and Health 2003. Obesity and Overweight. Available at www.who.int/dietphysicalactivity/publications/facts/obesity/en/ accessed on June 2005

19. Hedley AA, Ogden CL, Johnson CL, Carroll MD, Curtin LR, Flegal KM. Prevalence of overweight and obesity among US children, adolescents, and adults, 1999-2002. JAMA 2004;291:284750 .

20. Odgen CL, Carroll MD, Curtin LR, McDowell MA, Tabak CJ, Flegal KM. Prevalence of overweight and obesity in the United States, 1999-2004. JAMA 2006;295:1549-55.

21. Mokdad AH, Serdula MK, Dietz WH, Bowman BA, Marks JS, Koplan JP. The spread of the obesity epidemic in the United States, 1991-1998. JAMA 1999;282:1519-22.

22. Laitinen J, Power C, Jarvelin MR. Family social class, maternal body mass index, childhood body mass index, and age at menarche as predictors of adult obesity. Am J Clin Nutr 2001;74:287-94.

23. Olson CM. Nutrition and health outcomes associated with food insecurity and hunger. J Nutr 1999;129:512S-24S

24. Townsend MS, Peerson J, Love B, Achterberg C, Murphy SP. Food insecurity is positively related to overweight in women. $\mathrm{J}$ Nutr 2001;131:1738-45.

25. Jones SJ, Jahns L, Laraia BA, Haughton B. School-aged food insecure children who participate in food assistance are less likely to be at risk of overweight: Results from the PSID-CDS. Arch Pediatr Adolesc Med 2003;157:780-4.
26. Vozoris NT, Tarasuk VS. Household food insufficiency is associated with poorer health. J Nutr 2003;133:120-6.

27. Alaimo K, Olson CM, Frongillo EA, Briefel RR. Food insufficiency, family income, and health in US preschool and school-aged children. Am J Public Health 2001;91:781-6.

28. Kral JG. Preventing and treating obesity in girls and young women to curb the epidemic. Obes Res 1539;12:1539-46.

29. Yen J, Shelton JA. Increasing prepregnancy body mass index: Analysis of trends and contributing variables. Obestet Gynecol 2005;193:1994-8.

30. Lu GC, Rouse DJ, DuBard M, Cliver S, Kimberlin D, Hauth JC. The effect of the increasing prevalence of maternal obesity on perinatal morbidity. Am J Obstet Gynecol 2001;185:845-9.

31. Olson CM, Strawderman MS, Hinton PS, Pearson TA. Gestational weight gain and postpartum behaviors associated with weight change from early pregnancy to $1 \mathrm{y}$ postpartum. Int $\mathrm{J}$ Obes $2003 ; 27: 117-27$.

32. Carmichael S, Abrams B, Selvin S. The pattern of maternal weight gain in women with good pregnancy outcomes. Am J Public Health 1997;87:1984-8.

33. Keppel KG, Taffel SM. Pregnancy-related weight gain and retention: implication of the 1990 Institute of Medicine guidelines. Am J Public Health 1993;83:1100-3.

34. Winkvist A, Rasmussen KM, Lissner L. Associations between reproduction and maternal body weight: examining the component parts of a full reproductive cycle. Eur J Clin Nutr 2003;57:114-27.

35. Lederman SA. The effect of pregnancy weight gain on later obesity. Obstet Gynecol 1993;82:148-55.

36. Dixon JB, Dixon ME, O'Brien PE. Pregnancy after lap-band surgery: management of the band to achieve healthy weight outcomes. Obes Surg 2001;11:59-65.

37. Wittgrove AC, Jester L, Wittgrove P, Clark GW. Pregnancy following gastric bypass for morbid obesity. Obes Surg 1998;8:461-4.

38. Stevens J, Murray DM, Catellier DJ, Hannan PJ, Lytele LA, Elder JP, Young DR, Simons-Morton DG, Webber LS. Design of the Trail of Activity in Adolescent Girls (TAAG). Contemp Clin Trials 2005;26:223-33.

39. Miller-Perrin E, Flower KB, Garrett J, Ammerman AS. Preventing and treating obesity: Pediatricians' self-efficacy, barriers, resources, and advocacy. Ambul Pediatr 2005;5:150-6.

40. Tsai AG, Wadden TA. Systematic review: An evaluation of major commercial weight loss programs in the United States. Ann Intern Med 2005;142:56-66.

41. Olson CM, Strawderman MS, Reed RG. Efficacy of an intervention to prevent excessive gestational weight gain. Am J Obstet Gyn 2004;191:530-6.

42. Polley BA, Wing RR, Sims CJ. Randomized controlled trail to prevent excessive weight gain in pregnant women. Int $\mathrm{J}$ Obes 2002;26:1494-502.

43. O'Toole ML, Sawicki MA, Artal R. Structured diet and physical activity prevent postpartum weight retention. J Womens Health 2003;12:991-7.

44. Peterson KE, Sorensen G, Pearson M, Hebert JR, Gottlieb BR, McCormick MC. Design of an intervention addressing multiple levels of influence on dietary and activity patterns of low-income, postpartum women. Health Educ Res 2002;17:531-40.

45. Executive Summary. Obes Res 1998;6:51S-63S. 